In tho article referred to, however, it was intended, as was suggested near the beginning of the article, to discuss only the mechanical construction of the various instruments. Any detailed reference to the method of illumination, which is undoubledly an itern of considerable importanco in metallurgical microscopy, was also thereby oxcluded. When referring to items to which the user might attach importance bocause they suited his particular method of working, the writer had in mind the various methods of illurnination employed, including the universal vertical illuminator fitted to the Beck instrument, which permits of the use of various types of transparont and of opaque reflectors which are easily interchangeable and easily adjustablo in every roquired direction. Reference was also made in the article to the wide range of adjustment of the elements of the illuminating system provided by the British instruments. These adjustments facilitate the use of the methods of illumination mentioned by $\mathrm{Mr}$. Beck ; but, as was suggested, the method of obtaining the adjustments might be improved.

In the production by ordinary enginecring methods of the optical bench of the elongated triangular prism type, a certain manufacturing tolerance is necessary on the angle of the prism. A manufacturing tolerance is necessary also on the angle of the saddle. If shake is to be avoided, no such tolerance can be permitted on either of these components. The geometrically mounted saddle will fit the triangular prism at any part of its length without shakc, even though a reasonably large manufacturing toleranco has been allowed in the angle of the prism. When the saddle is in use, the forces brought to bear on it are not great ; the relative movement of the saddie and the prism is not great; and the wear is thus not severe. The aren of the contact surfaces need therefore not be at all large. A properly designed clamp for the saddle should produce a pressure uniformly distributed amongst the five points. The only result of this departure from the geometric principlo is to set up strains in the saddle. For effective clamping these strains need not be great, and the ordinary saddle is sufficiently robust to withstand them without perceptible deformation.

With regard to the focussing adjustments, it may be pointed out that the stage is subjected to varying loads. Frequently, fairly heavy objects are placed on it. These loads are effective on an overhanging stage whether the coarse adjustmont is clamped or not.

There are, certainly, various ways in which the necessary movements and adjustments of the several parts of the photomicrographic apparatus may be obtained. The method solected should be such as is likely to be most efficient in use, and tho design such as to be capable of being satisfactorily made at a reasonable cost.

$$
\text { THE WRITER OF THE AR'TICLE. }
$$

\section{Science and Philosophy.}

Permit me two comments on the references to my Huxley Lecture in the leading article in Nature of Oct. 22 .

In my judgment the writer put the eart before the horse when he suggested that philosophy had boen changing the "fundumental conceptions of science." By the ordinary mothods of science, prodigious advancos in knowledge have recently been made, ospecially in mathematics and physies, and it is philosophy that is ongaged in trying, in her usual way, to bring herself up-to-date.

The writer refers to an " emergent theory " as if it had been an important principle, by overlooking which my "polemic ngainst vitalism had missed its mark." He may not agree with me, but so far from overlooking that odd thoory, $T$ described its origin and explained how in my opinion it was a conspicuous example of the interpolation of an imaginary principle in an unfinished scientific story.

$$
\text { P. Chalmers Mitcheli. }
$$

My intention was not to cxalt philosophy at the expense of science, but to plead for co-operation between the two. I cannot agree with Dr. Mitchell that the recent great advances in mathematics and physics have come about sololy through the ordinary methods of science. Equally important has been the critical investigation of the fundamental concepts, for cxample, of time and space, which has gono on side by side with the discovery of new facts. Such criticism of concepts is generally regarded as a main function of philosophy, and if it bo carried out-as it should be-by the scientific worker himself, it rernains none the loss philosophy. In the sphere of biology we urgently need, it secms to me, this same combination of observation, experiment, and the critical study of fundamental conceptions.

I have not accused Dr. Mitchell of overlooking the theory of ernergence, and I even agree with him that in some of its forms it is regrettably vague. My point was rather that he appears to treat all forms of non-mochanistic doctrine as if they.were based upon dualistic vitalism. This is obviously not true, for example, of Dr. J. S. Haldane's views, or of Prof. A. N. Whitehead's "organic' theory of nature.

Tine Writer of tire ARticle.

\section{An Aspect of the Biochemistry of Sugars.}

IN reply to Mr. Levene's letter in Nature of Oct. 29 , I would direct attention to the following points :

(I) Even if the hypothesis of inversion in the hydrolysis of sugar phosphates in Nature is correct, it may well be difficult to find the conditions for the irnitation of the process in the laboratory. Mr. Levene has recently contributed a striking example in which inversion occurs with ono reagent but not with another.

(2) The behaviour of glucose-3-phosphoric acid (or is it allose-3-phosphoric acid ?) is highly interesting and important, but the glucose-galactose change involves position-4, where the stereochemical con. ditions are different. We know many cases - some are in the camphor group-in which direct replacement occurs as the result of stcric influences, although analogies indicate that inversion should be regarded as the normal event in these reactions.

(3) The evidence that the pentose-phosphoric acid from inosic acid (Levene and Jacobs, 1911) is $d$-ribose5 -phosphoric acid is inconclusive, becanse a $\delta$-xylonolactone-phosphorie acid might be stable in acid solution at $40^{\circ}$. Admittedly the evidence fuvours the view of Leveno and Jacobs, but it needs to bo sup. plemented by methylation methods.

(4) Assuming that the pentose-phosphoric acid is $d$-ribose-5-phosphoric acid, that doos not dispose of the main thesis, for the possibility exists that, in the original nucloic acid, the phosphoric acid is attached to the sugar molecule at more than one point (com pare Thannhauser). Moreover, the migration of the phosphoric acid residue from one position to nnother in the chain is a possibility that rnust bo kopt in mind.

In short, the subject bristles with so many theoretical and experimental difficulties that it is doubtful whether a full discussion is possiblo at the present time.

Finally, my suggestions were not put forward as firm conclusions; $I$ thought it wurth while to advance them in order to indicate what seemed to be a useful working hypothesis. R. RoBINSON.

Sept. 29.

No. 3027, VoL. 120] 